\title{
25 Research Square \\ The Detection of Wetlands And Wetland Fragmentation Using Sentinel 1 And 2 Imagery: The Example of Southern Nigeria
}

\section{Sani Idris Garba ( $\square$ idrisgarbasani@gmail.com )}

University of Leeds https://orcid.org/0000-0001-9620-8831

\section{Susanna Ebmeier}

University of Leeds

Jean-François Bastin

Province de Liege

\section{Danilo Mollicone}

Food and Agriculture Organization of the United Nations

Joseph Holden

University of Leeds

\section{Research Article}

Keywords: swamp, marsh, mangrove, optical indices, SAR polarimetric indices, random forest, uncertainty

Posted Date: December 6th, 2021

DOl: https://doi.org/10.21203/rs.3.rs-1094849/v1

License: @ (1) This work is licensed under a Creative Commons Attribution 4.0 International License. Read Full License 


\section{Abstract}

Wetland ecosystems play key roles in global biogeochemical cycling, but their spatial extent and connectivity is often not well known. Here, we describe an approach suitable for application on a $1000 \mathrm{~km}$ scale using Sentinel-1 and Sentinel-2 imagery, exploiting the implementation of Random Forest algorithm in Google Earth Engine. The approach was used to detect the spatial coverage of wetland types focusing on the case of southern Nigeria, thought to be one of the most wetland-rich areas of Africa. We compiled 1050 wetland and non-wetland control points for algorithm training and validation, primarily from visual interpretation of high-resolution ( $<1 \mathrm{~m}$ pixel) imagery. This allowed us to establish the relative importance of 18 input channels derived from Sentinel-1 polarimetric and Sentinel-2 indices for classification of wetland. We estimate that the swamps, marshes, mangroves, and shallow water wetlands of southern Nigeria cover 29,900 km² with $2 \%$ uncertainty of $460 \mathrm{~km}^{2}$. We found larger mangrove and smaller marsh extent than suggested by earlier, coarser spatial resolution studies. Average continuous wetland patch areas were $120 \mathrm{~km}^{2}, 11 \mathrm{~km}^{2}, 55 \mathrm{~km}^{2}$ and $13 \mathrm{~km}^{2}$ for mangrove, marsh, swamp, and shallow water respectively. Our final map with $10 \mathrm{~m}$ pixels also captures small patches of wetland, with $20 \%$ of wetland patches being $<1 \mathrm{~km}^{2}$; these were clustered around urban centres, suggesting anthropogenic wetland fragmentation. Our approach can now be used across rest of Africa and globally to detect wetlands and wetland change which, in turn, will be crucial for improved land-surface climate models and wetland conservation.

\section{Introduction}

Wetlands are one of the world's most important and productive ecosystem types, playing a vital role in climate change mitigation (Medugu, 2015), hydrological and biogeochemical cycles (Junk et al., 2013) and maintaining livelihoods (Hu et al., 2017; Wilen \& Bates, 2015). The southern part of Nigeria contains many wetlands which are thought to consist mainly of marshes, mangroves and freshwater swamps (Ayanlade \& Proske, 2016; Olalekan et al., 2014). However, great environmental pressure has been exerted on these ecosystems as result of land reclamation for agriculture and industrialization (e.g. Niger delta; Chidumeje et al., 2015), urbanization (e.g. Lekki lagoon of Lagos; Obiefuna et al., 2013) and contamination from pollution (e.g. oil spills; Igu \& Marchant, 2017; Ohimain, 1996). The regional extent of existing wetlands that need protecting, and the extent of wetland loss and degradation, has thus far only been quantified at coarse resolution. Although there are some global wetland maps, such as Global Land Cover GLC250-2010 (250 m pixels) and the Global Lakes and Wetlands Database (GLWD-3, 1 km pixels), studies by Gumbricht et al., (2017), Hu et al., (2017) and Xu et al., (2018) show inconsistencies between them due to differences in methods, data sources, and validation. Many wetland maps rely on data that can be decades old and, particularly in developing countries, with very limited ground truth data. It is therefore important to improve maps of these ecosystems, using a range of techniques, to get a complete picture of wetland area and to establish the range and extent of different wetland types and their fragmentation. Comprehensive wetland maps and an understanding of the nature of their fragmentation are needed to build economic assessments of wetland ecosystem service provision and to support decision-making by regional and international bodies seeking to protect wetland systems as well as for inclusion in coupled land-surface - climatic models (e.g. JULES / QUEST: Clark et al., 2011; Dadson et al., 2010). The latter is crucial since wetlands are important for land-atmosphere carbon dynamics, greenhouse gas exchange, and the water cycle.

Southern Nigeria is a low-lying region covering $\sim 147,000 \mathrm{~km}^{2}$ (between $4^{\circ} 00$ and $7^{\circ} 00 \mathrm{~N}$, and $3^{\circ} 00^{\circ}$ and $9^{\circ} 00^{\circ} \mathrm{E}$, Figure 1) and is thought to have the most extensive wetlands in west Africa (Gumbricht et al., 2017; Uloacha, 2004). The only wetland maps that currently span all of southern Nigeria are from global projects (e.g., GLWD-3) 
and have relatively low resolution $(1 \mathrm{~km})$. However, there are some small-scale studies that have mapped a few local wetlands in the region using satellite imagery (e.g. Ayanlade \& Proske, 2016; Obiefuna et al., 2013; Taiwo \& Areola, 2009; locations shown in Figure 1). The accuracy of these small-scale studies has yet to be assessed due to absence of suitable ground truthing data. Furthermore, the techniques used in these studies are not suitable for region or country-scale wetland mapping.

\subsection{Wetland definitions}

Generally, wetlands can be classified on the basis of hydrology, soil type and vegetation. They include marshes (freshwater or saline waterlogged land areas that are periodically flooded, dominated by herbaceous plants), swamps (mineral soil wetlands dominated by trees with seasonal flooding), bogs (rain-fed peatlands, which can be with or without trees) and fens (groundwater-fed peatlands, which can be with or without trees) (Mitsch \& Gosselink, 2015). In this study, we consider swamps, marshes, shallow water (including human-made wetlands and lakes) and the swamp subtype of mangroves (coastal, characterised by salt-tolerant trees and shrubs), and attempt to distinguish between these categories in our mapping.

Gradual transitions between wetland types can make clear demarcation challenging and a wetland type can furthermore have different characteristics in different parts of the world. Choice of wetland types in mapping is therefore a pragmatic decision depending both on local wetland characteristics and the separability of different wetland types in observations. The presence of peatlands (fens) across the southern region of Nigeria has been suggested by other mapping studies (e.g. CIFOR, 2016). The Nigerian government, however, suggested that the areas mapped by CIFOR as peatland are more likely to be mangrove/swamps (FREL, 2019). One potential source of confusion is that tropical 'peat swamps' are often referred to in the literature as there is a lack of an agreed tropical peatland classification system. Some swamps can have organic peat deposits while others may have a mineral substrate. To avoid confusion, we strictly classify swamps for our control points as tree-dominated mineral soil wetland systems which may have minimal peat cover. Given this definition, peatland and swamp may in some cases still have similar Earth Observation signatures but would not be confused if ground-truthed.

\subsection{Identification of wetlands from satellite imagery}

Satellite images have been used successfully to identify and map different wetland types around the world (Fei et al., 2011; Guo et al., 2017; Klemas, 2011; Kuenzer et al., 2011; Mahdianpari et al., 2019). Interpretation of multitemporal imagery in particular can aid classification of dynamic wetlands and their separation from other ecosystems (Mahdianpari et al., 2018, Ozesmi \& Bauer, 2002). Many wetlands have seasonal characteristics based on changes in water level and vegetation that can assist their detection using remote sensing. For example, marshes experience drying of vegetation and a decrease in water level during the dry season or low tide periods (Hudson et al., 2006). This can be observed using optical images from a decrease in the reflectivity in the near infrared and a slight increase in reflectivity to the red band due to suspended particles settling out at low water levels (Hudson et al., 2015). Marsh plants are often annuals and their characteristics change seasonally. Swamps are characterized by both saturated soils during the growing season and seasonal standing water, with a major decrease in swamp water level only in very dry seasons (Schlaffer et al., 2016). Mangroves do not tend to possess obvious seasonal features but can be distinguished based on the presence of mangrove vegetation and permanent standing water. 
The availability of vast amounts of open access satellite data, and the growth of advanced machine learning tools integrated with robust cloud computing resources has recently made multi-temporal datasets more accessible (Mahdianpari et al., 2018). Previous studies have used multi-temporal Landsat imagery to classify wetlands both with unsupervised classification algorithms (e.g. K-means and ISODATA; Mwita et al., 2012; Ramsey \& Laine, 1997) and with supervised classification schemes (Bwangoy et al., 2010; Wright \& Gallant, 2007). The most commonly used approach has involved use of optical indices such as Normalized Differential Vegetation Index (NDVI), Land Surface Water Index (LSWI), Normalized Differential Water Index (NDWI), Tasseled Cap Wetness Index (TCWI), and Modified Soil Adjusted Vegetation Index (MSAVI2) (Chatziantoniou et al., 2017; Kaplan \& Avdan, 2017; Mahdianpari et al., 2019; Dong et al., 2014; Xing et al., 2018). However, Synthetic Aperture Radar (SAR) C-band multi polarization radar data has also been used with supervised classification to discriminate between wetland types (Baghdadi et al., 2010), with cross polarization (HV, VH) providing better discrimination between some wetland classes. SAR can penetrate cloud cover, is independent of solar radiation, and is sensitive to structural, textural, and dielectric characteristics of surface features (Bwangoy et al., 2010; Mahdianpari et al., 2018; Mahdianpari et al., 2017; Moser et al., 2016), whereas optical sensors are sensitive to the reflective and spectral characteristics of the surface (Mahdianpari et al., 2018). Combining multiple optical and SAR indices to classify different wetland types therefore has great potential for wetland classification (Kaplan, et al., 2019; Mahdavi et al., 2018; Salehi et al., 2018).

Here, we map the extent of wetlands and categorize the different wetland types for southern Nigeria with a $10 \mathrm{~m}$ pixel size, leveraging the open access SAR and optical images acquired from Sentinel- 1 and Sentinel-2 and exploiting cloud computing through Google Earth Engine (GEE). We hypothesized that we would find a greater spatial coverage of wetlands compared to earlier estimates due to high resolution mapping of small wetlands that were previously undetected. We also hypothesized that wetland fragmentation would be greatest near urban areas.

\section{Materials And Methods}

Our approach to mapping the wetlands of southern Nigeria involves the integration of indices from both optical and radar imagery (Figure 2), and classification of imagery using the implementation of the Random Forest (RF) algorithm in Google Earth Engine (Gorelick et al., 2017). We use seasonal composite images in order to (a) maximise the number of cloud-free pixels and (b) incorporate the seasonal variations in wetland characteristics into our classification (Sections 2.1.1 to 2.1.2). We selected the most effective variables for classification in southern Nigeria using an estimation of relative importance (Section 3.1). This required the compilation of a new dataset of wetland and non-wetland control points for training and validation (Section 2.1.3, Supplementary Information).

\subsection{Dataset, preprocessing and analysis 2.1.1 Sentinel-2 imagery}

Wetlands can generally be distinguished from other ecosystems using near infrared (NIR), short wave infrared (SWIR) and visual bands, with different types of wetland producing distinctive spectral responses. For example, shallow water and areas of flooded vegetation absorb strongly at NIR wavelengths (Mahdianpari et al., 2018; Younggi et al., 2015). The zone between visible red and NIR, known as the red edge, also provides useful 
information about chlorophyll in vegetation and moisture content which aids wetland identification (Amani et al., 2017) while SWIR region is very sensitive to vegetation and soil moisture which are key features of wetlands. Sentinel-2 has four bands at $10 \mathrm{~m}$ pixel size, which is an improvement over Landsat $(30 \mathrm{~m})$ and MODIS (250-1000 $\mathrm{m})$. Sentinel-2 also has better spectral resolution than Landsat in the near-infrared region (band 8 and $8 \mathrm{~A}$ ) and includes three vegetation red edge bands with $20 \mathrm{~m}$ spatial resolution.

The southern part of Nigeria experienced a tropical climate with a well-defined wet and dry season. The average annual rainfall ranges from 2000 to $4021 \mathrm{~mm}$ (Adejuwon, 2012), with precipitation increasing from north of the Niger Delta towards the coast. Southern Nigeria is covered by dense cloud during rainy seasons, so we use an initial selection criterion of cloud fraction $<20 \%$ for each of 345 Sentinel-2 images from 2018 and apply a cloud mask to remove cloud and cirrus-cover (using the quality assurance bands available through GEE) before formation of a composite images (Figure 2). These are constructed from the median value for each pixel in 345 Sentinel-2 images acquired between January and November 2018 and are dominated by dry season (January to March) values.

We use blue $(0.496 \mu \mathrm{m}$, band 2$)$, green $(0.560 \mu \mathrm{m}$ band 3$)$, red $(0.665 \mu \mathrm{m}$, band 4$)$, and NIR $(0.835 \mu \mathrm{m}$, band 8$)$, shortwave infrared 1 (SWIR1 $1.613 \mu \mathrm{m}$, band 11) and short-wave infrared 2 (SWIR2 $2.202 \mu \mathrm{m}$, band 12) bands to derive optical indices used for classification: NDVI (Chatziantoniou et al., 2017; Dong et al., 2014; G. Kaplan \& Avdan, 2017; Mahdianpari et al., 2019; Xing et al., 2018), NDWI (Chatziantoniou et al., 2017; Kaplan \& Avdan, 2017; Mahdianpari et al., 2018; Xing et al., 2018), MNDWI (Ashraf \& Nawaz, 2015; Chen et al., 2013; Ogilvie et al., 2015) and TCWI (Tana, Letu, Cheng, \& Tateishi, 2013; Xing et al., 2018) (Figure 3b-e),

$\mathrm{NDVI}=\frac{N I R_{B 8}-\mathrm{RED}_{B 4}}{N I R_{B 8}+R E D_{B 4}}(1)$

$\mathrm{NDWI}=\frac{N I R_{B 8}-\mathrm{SWIR}_{B 12}}{N I R_{B 8}+S W I R_{B 12}}(2)$

MNDWI $=\frac{G_{B 3}-\operatorname{SWIR}_{B 12}}{G_{B 3}+\operatorname{SWIR}_{B 12}}(3)$

$\mathrm{TCWI}=0.1509(B 2)+0.1973(B 3)+0.3279(B 4)+0.3406(B 8)-0.7112(B 11)-0.4572(B 12)(4)$

\subsubsection{Sentinel-1 radar imagery}

Radar wavelengths penetrate cloud and are very sensitive to differences in moisture content and surface roughness, making them ideal for wetland mapping in areas with dense cloud cover. High moisture content generally results in an increase in backscatter, and radar reflected by a water layer and backscattered by a doublebounce from ground and tree trunk creates contrast between the flooded and non-flooded terrain (Bwangoy et al, 2010b; Moser et al., 2016).

We use the Ground Range Detected interferometric wide-swath Sentinel-1 images in ascending orbit from 2018 available through GEE, which are projected onto a regular $10 \mathrm{~m}$ grid. Dual VV/VH polarisation imagery was available at an average acquisition interval of 12 days over southern Nigeria. VV polarization (vertically transmitted, vertically received backscatter) is sensitive to surface roughness and soil moisture and can discriminate flooded from non-flooded vegetation (Mahdianpari et al., 2018). It also produces distinctive returns for herbaceous wetlands with low or sparsely vegetated areas especially in the early growth stages before canopy 
closure (Baghdadi et al., 2010). VH (vertically transmitted, horizontally received backscatter) known as cross polarization produces signals affected by volume scattering within the vegetation canopy and it is very sensitive to vegetation structures (Steele-Dunne et al., 2017). We corrected for incidence angle (Hird, Delancey, \& Mcdermid, 2017) and reduced radar speckle using an adaptive sigma Lee filter on the GEE platform.

Since SAR backscatter is unaffected by cloud cover, we are able to incorporate information from dry (JanuaryMarch) and wet seasons (April-July and September-November) into our classification scheme. We calculated the normalized difference and ratio features for each image as:

Ndiff $=\frac{V H-V V}{V H+V V}(5)$

Nratio $=\frac{V V}{V H}(6)$

where VH means a vertically transmitted, horizontally received SAR backscatter $\sigma^{0}$ from the Sentinel- 1 sensor, while VV stands for a vertically transmitted and received SAR backscatter signal from the same sensor (Hird et al., 2017). We constructed dry and wet season composites that select the median backscatter value for each pixel, shown in Figure $4 \mathrm{~b}$ and $\mathrm{c}$ as RGB images where dry season (January-March), wet season (April-July) and end of the wet season (Sept-Nov) are the red, blue and green channels, respectively.

\subsubsection{Compilation of control point data}

We compiled information about the location and characteristics of wetlands in southern Nigeria from multiple sources. Our reference data were obtained from the Food and Agriculture Organization (FAO) global dryland assessment (Bastin et al., 2017), Ramsar Sites database (2019), other organization reports, journals, and academic theses (both PhD and MSc) (see Supplementary Information). The FAO reference points were compared with control sites from Ramsar and other studies, then verified by visual interpretation of Digital Globe very high spatial resolution images ( $<1 \mathrm{~m}$ pixels) made available for visualization through Google Earth. Our database comprises a total of 1050 sample points for wetland and non-wetland locations. The reference data were grouped into four wetland (swamp, mangrove, marsh, shallow water) and four non-wetland (deep water, urban/bareland, agricultural land, forest) categories. The photo-interpreted database consists of both wetland and non-wetland cover classes with many subtypes, while only wetland control points were acquired from other studies.

\subsection{Random Forest classification}

$\mathrm{RF}$ is a non-parametric classifier (i.e. it does not make strong assumptions about the form of the mapping function), comprised of a collection of tree classifiers, and can handle high dimensional remote sensing data (Belgiu \& Dra, 2016). RF classification involves assigning a label to each pixel based on the majority vote of 'trees'. The ' trees' are grown a node is splitted using a random selection of the subset input variables, which reduces overfitting and yields a more robust classification than other classifiers (Breiman, 2001). In the RF algorithm, we need to specify the parameters in order to produce the forest trees: the number of decision trees to be generated (Ntree); and the number of variables to be selected and tested for the best split when growing the trees (Mtry). The parameter Ntree was assessed for the values of $100-600$ : a value of 500 was selected as error rates for all classification models were constant beyond this point. We tested the importance of sixteen variables (Band 2, Band 3, Band 4, Band 6, Band 7, Band 8, Band 11, Band 12, NDWI, NDVI, MNDWI, TCWI, $\frac{V H-V V}{V H+V V}, \frac{V V}{V H}$ (wet and dry)), as input channels for the RF classification. We then selected six input variables that were most important for 
classification accuracy (see Section 3.1). A total of 700 training points spanning different landcover classes were used to train the RF classifier on the GEE platform. All classifications were based on the same training data. The remaining 350 control points were held back for validation (e.g., Liu et al., 2018). We divided the control points between training and validation data to ensure a spread between landcover classes, and otherwise to make their spatial distribution as even as possible across southern Nigeria. The classification was carried out with each index separately, before selecting the best combination to produce a final wetland map. We classified eight different landcover classes: mangrove, swamp, marsh, shallow water, forest, cultivated land, deep water, builtup/bare land. When selecting input variables used for our final RF classification, we assessed each of the optical and SAR indices for (1) the predictive power of each individual variable (Section 3.1) and (2) the ability to distinguish between wetland classes (Section 3.2).

\section{Results}

\subsection{Feature selection for Random Forest classification}

We examine the significance of each input variable by calculating variable importance after training the RF classifier. The importance of a variable in this RF model is assessed using the total decrease in impurity across all trees in the forest for a specific choice of variable to split a node, where impurity refers to the probability of a classification being wrong if it were assigned according only to the distribution of classes in the data. The numerical values for importance assigned to each variable is the sum of the reduction in error of the splitting variable accumulated over the entire tree. Higher variable importance means that the variable played a significant role in the classification, while a low importance means only limited added value by that variable. Figure 5 illustrates the input variables and their corresponding importance for discriminating wetland classes.

As shown above, all the extracted variables from the Sentinel-1 seasonal composite appears to have higher predictive power than the optical indices. With regards to variables extracted from Sentinel-2 composite, the optical indices tend to possess higher significance when compared with the individual bands. Among the indices, MNDWI and TCWI have the higher information available for wetland cover prediction. The total of six most important variables (MNDWI, TCWI, $\left(\frac{V H-V V}{V H+V V}, \frac{V V}{V H}\right.$ (wet and dry)) from Sentinel-1 and Sentinel-2 were selected for our final classification.

\subsection{Classification validation}

The results of RF classifications for each index and for our preferred combination of indices (MNDWI, TCWI, ( $\frac{V H-V V}{V H+V V}, \frac{V V}{V H}$ (wet and dry)) were evaluated using one third (350) of the total control points spatially selected from each class on a random basis. The overall accuracy describes the effectiveness of the overall classification, which can be determined by dividing the sum of correctly classified sample by the total referenced sample. The producer's accuracy shows how well the referenced sample is represented in the classified map, while the user`s accuracy indicates the chances that a classified pixel of an individual landcover actually represent the same category on ground. The agreement, beyond chance, of a classification and the real land cover can be described by the Kappa coefficient (e.g., Ayanlade, 2014). The Kappa coefficient is more useful than the overall accuracy as it provides a measure of how the classification performs in comparison to the probability of randomly assigning pixels to their correct categories. With the exception of NDVI, the classification results using spectral indices from optical imagery were more accurate than those from SAR imagery alone (Table 1). However, the integration of the 
SAR normalized difference and ratio images described in Section 2.3.2 with MNDWI and TCWI yield the highest accuracy. We attribute this to the improvement in the accuracy of the identification of marsh, swamp and mangrove classes due to the information about vegetation structure captured by SAR imagery (Figure 4b \&c).

Table 1

Overall accuracies and Kappa coefficients obtained from classification of wetland versus non-wetland in this study. Perfect classification of control points would yield a Kappa value of 1. S1+S2 represents our preferred combination of MNDWI and TCWI with the SAR polarimetric indices.

\begin{tabular}{|lll|}
\hline Indices & Overall accuracy (\%) & Kappa coefficient \\
\hline NDVI & 73.10 & 0.68 \\
\hline NDWI & 77.16 & 0.72 \\
\hline MNDWI & 83.78 & 0.82 \\
\hline TCWI & 83.74 & 0.79 \\
$\frac{V H-V V}{V H+V V}$ (wet and dry) & 85.14 & 0.83 \\
\hline$\frac{V V}{V H}$ (wet and dry) & 74.30 & 0.72 \\
\hline MNDWI+TCWI+ $\frac{V H-V V}{V H+V V}+\frac{V V}{V H}$ & 88.40 & 0.85 \\
\hline
\end{tabular}

For all landcover classes, classification using a combination of optical and radar data resulted in a higher accuracy than using any of the individual indices in isolation. Our preferred classification (MNDWI+TCWI+ $\frac{V H-V V}{V H+V V}$ $+\frac{V V}{V H}$ in Tables 1 and 2) performs as well as any other index in its classification of mangroves (157 control sites) and swamps (149 control sites) (Table 2), and better than any other index for classification of marsh (63 control sites). All indices had lower producers and users accuracies in identifying marsh, which was often misidentified as shallow water or swamp. Classification based on SAR data alone provided highest producers and users accuracies for identifying shallow water and built-up/bare land, but lower accuracies for all other non-wetland classes (Table 2). Overall, the classification of wetland classes was less accurate than for non-wetland classes.

The combined use of optical indices (MNDWI and TCWI) and SAR features $\left(\frac{V H-V V}{V H+V V}, \frac{V V}{V H}(\right.$ wet and dry $\left.)\right)$ resulted in greater accuracy for all the wetland classes than the use of either Sentinel-1 or Sentinel-2 imagery in isolation, and so this combination was used to produce our final wetland map. 
Table 2

Producer`s and User's accuracy (\%) for each index in our study.

\begin{tabular}{|c|c|c|c|c|c|c|c|c|c|c|c|c|c|c|c|c|}
\hline $\begin{array}{l}\text { Total } \\
\text { number } \\
\text { of } \\
\text { control } \\
\text { points }\end{array}$ & \multicolumn{2}{|c|}{157} & \multicolumn{2}{|c|}{149} & \multicolumn{2}{|l|}{63} & \multicolumn{2}{|c|}{128} & \multicolumn{2}{|c|}{138} & \multicolumn{2}{|c|}{151} & \multicolumn{2}{|c|}{140} & \multicolumn{2}{|c|}{124} \\
\hline $\begin{array}{l}\text { Wetland } \\
\text { type }\end{array}$ & \multicolumn{2}{|c|}{ Mangrove } & \multicolumn{2}{|c|}{ Swamp } & \multicolumn{2}{|c|}{ Marsh } & \multicolumn{2}{|c|}{$\begin{array}{l}\text { Shallow } \\
\text { water }\end{array}$} & \multicolumn{2}{|c|}{$\begin{array}{l}\text { Deep } \\
\text { water }\end{array}$} & \multicolumn{2}{|c|}{$\begin{array}{l}\text { Built } \\
\text { up/bare } \\
\text { land }\end{array}$} & \multicolumn{2}{|c|}{ Forest } & \multicolumn{2}{|c|}{$\begin{array}{l}\text { Cultivated } \\
\text { land }\end{array}$} \\
\hline $\begin{array}{l}\text { Accuracy } \\
\text { type }\end{array}$ & PA & UA & PA & UA & PA & UA & PA & UA & PA & UA & PA & UA & PA & UA & PA & UA \\
\hline NDVI & 54 & 57 & 73 & 59 & 52 & 63 & 64 & 65 & 81 & 84 & 68 & 67 & 67 & 63 & 78 & 80 \\
\hline NDWI & 73 & 65 & 72 & 68 & 62 & 65 & 68 & 66 & 82 & 79 & 67 & 61 & 86 & 90 & 75 & 79 \\
\hline MNDWI & 89 & 83 & 81 & 79 & 72 & 69 & 73 & 67 & 90 & 88 & 89 & 94 & 81 & 92 & 77 & 58 \\
\hline TCWI & 82 & 80 & 72 & 77 & 67 & 64 & 72 & 75 & 86 & 84 & 86 & 88 & 80 & 85 & 77 & 82 \\
\hline$\frac{V H-V V}{V H+V V}$ & 89 & 88 & 81 & 87 & 67 & 64 & 78 & 80 & 96 & 94 & 94 & 94 & 66 & 69 & 77 & 79 \\
\hline$\frac{V V}{V H}$ & 75 & 73 & 88 & 81 & 57 & 66 & 76 & 75 & 92 & 90 & 94 & 88 & 63 & 57 & 65 & 61 \\
\hline $\begin{array}{l}\text { MNDWI } \\
+\mathrm{TCWI}+ \\
\frac{V H-V V}{V H+V V} \\
+\frac{V V}{V H}\end{array}$ & 89 & 78 & 92 & 90 & 72 & 70 & 97 & 95 & 98 & 87 & 97 & 97 & 92 & 94 & 79 & 78 \\
\hline
\end{tabular}

Our final wetland cover map (Figure 6a) shows the distribution of all land-cover classes across the extensive area of southern Nigeria. Both the wetland and non-wetland cover are well delineated with an estimated mapping accuracy of $88 \%$. The detailed inset in Figure $6 \mathrm{~b} \& \mathrm{c}$ shows how shallow water (e.g., Oguta lake, Figure 6b) and swamp (e.g., Upper Orashi swamp forest) are correctly distinguished from other landcover classes at two Ramsar wetland locations. We make an assessment of the spatial distribution of uncertainty in our wetland map by comparing it to a map produced from a randomly selected subset $(70 \%)$ of control points with the map produced using the entire dataset (Figure $6 \mathrm{~d}$ ). On Figure $6 \mathrm{~d}$ we show locations where land cover classifications agree for the two maps a value of 1 (white), and those that disagree a value of zero (black). We found that mismatches mostly lie on swamp and marsh landcover classes (Figure 6d), with fewer found to lie on mangrove and shallow water.

\subsection{Wetland spatial extent}

We estimate that the wetlands of southern Nigeria cover a total area of $29,900 \mathrm{~km}^{2}$ which is over one fifth of the area of the whole region. The dominant wetland type is swamp which made up $44 \%$ of the total wetland area followed by mangrove (31\%), marsh (20\%) and shallow lakes (5\%) (Figure 7). The vast majority of these wetlands are located in the coastal region of the Niger delta and Lagos. Our estimate of total wetland cover is less than the estimate by Center for International Forestry Research (CIFOR) $\left(31,829 \mathrm{~km}^{2}\right)$ but larger than GLWD $\left(24,408 \mathrm{~km}^{2}\right)$ (Figure 7), mainly resulting from our larger mapped area of mangrove and our identification of fewer marsh wetlands. While the maps look similar when viewed at low resolution, they are quite different in detail (Figure 7). 


\section{Discussion}

\subsection{Wetland extent and fragmentation}

We calculated the average continuous patch size for each wetland class using the total pixel count of connected pixels for continuous patches, which we define as pixels that share face boundaries. We found mean continuous wetland patches of $120 \mathrm{~km}^{2}, 11 \mathrm{~km}^{2}, 55 \mathrm{~km}^{2}$ and $13 \mathrm{~km}^{2}$ for mangrove, marsh, swamp, and shallow water respectively. The maximum patch size was $2740 \mathrm{~km}^{2}, 1530 \mathrm{~km}^{2}, 160 \mathrm{~km}^{2}$ and $50 \mathrm{~km}^{2}$ with a standard deviation of $660 \mathrm{~km}^{2}, 765 \mathrm{~km}^{2}, 25 \mathrm{~km}^{2}$ and $26 \mathrm{~km}^{2}$ for these wetland types respectively. Larger patches of wetland are found along the coastal areas while smaller fragments are mostly located around urban areas suggesting a role for anthropogenic fragmentation of wetlands. Mangroves tended to be located in zones with lower population density. There were a large number of small wetland fragments, mostly of single pixel patches, especially for the marsh class (Figure 8). These smaller patches were distributed across the map but had higher uncertainty relative to larger patches. Understanding wetland fragmentation and its impacts on biodiversity and ecosystem services, and the role of both larger and smaller wetland patches in landscapes requires further work, but our dataset provides a starting point for enhanced modelling of such effects.

The extent of wetland in southern Nigeria was found to be larger in our study when compared to some previous studies but, contrary to our hypothesis was smaller than the estimate by CIFOR (Figure 7a). This discrepancy could be due to a combination of factors including differences in wetland landcover class definitions (e.g. in CIFOR's global wetland database https://www.cifor.org/global-wetlands/ swamps and bogs are classed as one type of wetland, while many floodplain wetlands appear to be swamps in our wetland map), classification methodology, timeframe (e.g. wetland loss or creation between different studies), data resolution and time of acquisition. For example, more conservative methods used by previous studies based on combining existing maps with other data sources may have resulted in exclusion of a large proportion of the swamp and mangrove that we identify here. Another major difference is our use of satellite imagery with higher resolution (10 $\mathrm{m}$ pixel size, relative to $1 \mathrm{~km}$ for GLWD) which improves our ability to identify small-scale wetlands (see Figure 9) and aids in discriminating wetland and non-wetland features. Some areas where wetlands have not previously been reported (e.g., around Akampka in Cross Rivers) have been mapped in our study. Some studies have suggested that the GLWD may underestimate wetland extent because of low resolution input data (Gumbricht et al., 2017), so wetlands much smaller than $1 \mathrm{~km}^{2}$ are missed. About $20 \%$ of the wetlands that we identify in our new map have spatial extents of $<1 \mathrm{~km}^{2}$ (100 pixels). A series of small wetlands may be very important at a landscape scale in terms of water, nutrient and carbon cycling dynamics (Blackwell and Pilgrim, 2011) and so our work indicates how higher resolution wetland mapping may be important for improving regional and global environmental models.

\subsection{Sources of uncertainty}

The most important sources of uncertainty in this study come from (1) the subtlety of the differences in remote sensing signals between some wetland classes, and (2) the distribution and characteristics of the control sites used as the reference for different land-cover types. Specifically, we expect uncertainties to be introduced by both a lower number of control sites for marshes and similarities in the remote sensing expression of marshes vs. mangroves, especially at $1610 \mathrm{~nm}$ and $2190 \mathrm{~nm}$. We assess our uncertainties by comparing classifications made using the entire control point dataset with those produced using only a subset of control points selected at random for each wetland class (see Figure $6 \mathrm{~d}$ ). The mismatched pixels from each class were multiplied with the 
pixel area to obtain the mismatched area for each class. Swamp, with a total area of $13,000 \mathrm{~km}^{2}$ had the highest uncertainty of $250 \mathrm{~km}^{2}$ followed by marsh (area of $6,000 \mathrm{~km}^{2}$ ) with uncertainty of $123 \mathrm{~km}^{2}$. Lower uncertainty was estimated for mangrove $\left(9,000 \mathrm{~km}^{2}\right)$ at $72 \mathrm{~km}^{2}$ and shallow water $\left(1,616 \mathrm{~km}^{2}\right)$ with $14 \mathrm{~km}^{2}$. While this approach gives some indication of the uncertainties associated with our classification accuracy and limitations in the number of control points, it does not include systematic uncertainties associated with our choice of landcover classes. However, more than $98 \%$ of the control points accurately matched the classified land-cover class. Based on control point accuracy values for each wetland type (Table 2) there was a higher error with marshes due to their misinterpretation as mangroves and bare land / settlement features. A higher uncertainty occurred in areas around Ovia (south-west Edo state), northern parts of Ogun state and around Ndokwa in eastern Delta state due to the number of smaller patches of marsh. There were no control points for fen peatlands. However, our analysis suggests that areas mapped by other studies as peatlands (e.g., around Apoi creek forest) (refer to Figure 1a) in southern Nigeria are swamps (with total of 149 control points), for which we had a high confidence in their classification.

\subsection{Applicability to different settings}

Our novel study adds to a small number of regions around the world (e.g., Hird et al., 2017; Kaplan \& Avdan, 2018; Mahdianpari et al., 2019; Slagter et al., 2020) that use different approach to map wetlands. The wetlands of southern Nigeria are thought to represent about $19 \%$ of west African wetland and $3 \%$ of the total wetlands in sub Saharan Africa (Rebelo et al., 2010). Nigerian wetland ecosystems are similar to those in the rest of west Africa, so we expect that similar classification approaches could be adopted for this region. Our methodological approach could be expanded to explore wetland areas across the wider African continent as well as globally. Furthermore, our technique can be used to globally detect changes and connectivity/fragmentation of wetland ecosystem in response to human action such as urbanization. Using data from different seasons is important for mapping and distinguishing between different types of wetland extents. For example, seasonal data has played an important role in identification of shallow water and marshes (Figure 6a). Seasonal data will be essential for mapping the wetlands in the arid regions of Africa, where wetlands exhibit dramatic seasonal cycles (e.g. the Sebkhel el Kelbia of Tunisia). Challenges of producing high-resolution datasets over large spatial areas can be minimized by employing the SAR polarimetric feature and optical indices which help to distinguish between types of vegetation. Wetland types such as peatlands which were not covered in this study should be mapped using suitable control points to aid classification. There is also a need to incorporate elevation/topographic data and a diverse range of multi-temporal datasets in order to improve the identification of wetlands across different terrain, such as valley bottom wetlands. This will help to capture the hydro geomorphological properties of the wetlands.

\section{Conclusions And Implications}

Our novel study tested the potential of Sentinel-2 optical indices and Sentinel-1 SAR polarimetric features used in combination to map four wetland types. For southern Nigeria we were able to achieve a mapping accuracy of $88 \%$ by integrating optical indices and SAR polarimetric features from different seasons using Random Forest classification. We estimate that in 2018 southern Nigeria contained $29,900 \mathrm{~km}^{2}$ of wetlands with an uncertainty of $460 \mathrm{~km}^{2}$, covering $20 \%$ of the region. We found a large number of small wetland patches, particularly around urban areas, suggesting that human action may be enhancing wetland fragmentation in the region, in line with our fragmentation hypothesis. Wetland protection organizations can now more adequately assess the spatial 
coverage of these ecosystems, and undertake more adequate change detection and take action, while modellers can utilise our higher resolution land surface data.

\section{Declarations}

\section{Supplementary Material}

The ground control data are available at the Research Data Leeds repository (DOI to be added upon paper acceptance).

\section{Acknowledgements:}

This project was funded by a studentship awarded to SIG under the Petroleum Technology and Development Fund (PTDF) Nigeria. The photo-interpretation dataset was part of the global dryland assessment which was conducted in the region by the Food and Agriculture Organization and the National Space Research and Development Agency of Nigeria. SKE is supported by a NERC Independent Research Fellowship (NE/R015566/1) and is a member of the NERC-BGS Centre for the Observation and Modelling of Earthquakes, Volcanoes and Tectonics (COMET).

Funding The sources of funding were mentioned in the Acknowledgements section.

Code Availability Not applicable.

Conflict of Interest Authors declare no conflict of interests.

Ethics Approval Not applicable.

Consent to Participate Not applicable.

Consent for Publication Not applicable

\section{Authors Contribution}

Sani Idris Garba: Conceptualization, Methodology, Writing of Original Draft, Formal analysis

Susanna Ebmeier: Conceptualization, Review \& Editing, Resources, Supervision

Jean-François Bastin: Review \& Editing, Data Curation

Danilo Mollicone: Review \& Editing, Data Curation

Joseph Holden: Conceptualization, Review \& Editing, Resources, Supervision

\section{References}

1. Adejuwon JO (2012) Rainfall seasonality in the Niger Delta Belt. Nigeria 5(2):51-60. https://doi.org/10.5897/JGRP11.096

2. Amani M, Salehi B, Mahdavi S, Granger J (2017) Spectral analysis of wetlands in Newfoundland using Sentinel 2A and Landsat 8 imagery. IGTF 2017 - Imaging and Geospatial Technology Forum 2017, ASPRS Annual Conference, (May) 
3. Ashraf M, Nawaz R (2015) A Comparison of Change Detection Analyses Using Different Band Algebras for Baraila Wetland with Nasa's Multi-Temporal Landsat Dataset. Journal of Geographic Information System 07(01):1-19. https://doi.org/10.4236/jgis.2015.71001

4. Ayanlade A (2014) Remote Sensing of Environmental Change in the Niger Delta, Nigeria

5. Ayanlade A, Proske U (2016) Assessing wetland degradation and loss of ecosystem services in the Niger Delta, Nigeria. Marine and Freshwater Research 67(6):828-836. https://doi.org/10.1071/MF15066

6. Baghdadi N, Bernier M, Gauthier R, Neeson I (2010) Evaluation of C-band SAR data for wetlands mapping, 1161. https://doi.org/10.1080/014311601750038857

7. Bastin J-F, Berrahmouni N, Grainger A, Maniatis D, Mollicone D, Moore R, Mamane B (2017) Comment on "The extent of forest in dryland biomes.. " Science 358(6365):635-638. https://doi.org/10.1126/science.aao1309

8. Belgiu M, Dra L (2016) ISPRS Journal of Photogrammetry and Remote Sensing Random forest in remote sensing: A review of applications and future directions. 114:24-31.

https://doi.org/10.1016/j.isprsjprs.2016.01.011

9. Breiman LEO (2001) Random Forests. Mach Learn 45:5-32

10. Bwangoy JRB, Hansen MC, Roy DP, Grandi G, De, Justice CO (2010) Wetland mapping in the Congo Basin using optical and radar remotely sensed data and derived topographical indices. Remote Sens Environ 114(1):73-86. https://doi.org/10.1016/j.rse.2009.08.004

11. Chatziantoniou A, Petropoulos GP, Psomiadis E (2017) Co-Orbital Sentinel 1 and 2 for LULC mapping with emphasis on wetlands in a mediterranean setting based on machine learning. Remote Sensing 9(12). https://doi.org/10.3390/rs9121259

12. Chen $Y$, Huang C, Ticehurst C, Merrin L, Thew P (2013) An evaluation of MODIS daily and 8-day composite products for floodplain and wetland inundation mapping. Wetlands 33(5):823-835.

https://doi.org/10.1007/s13157-013-0439-4

13. Chidumeje NPO, Lalit K, Subhashni T (2015) The Niger Delta wetland ecosystem: What threatens it and why should we protect it? Afr J Environ Sci Technol 9(5):451-463. https://doi.org/10.5897/AJEST2014.1841

14. Clark DB, Mercado LM, Sitch S, Jones CD, Gedney N, Best MJ, Cox PM (2011) The Joint UK Land Environment Simulator (JULES), model description - Part 2: Carbon fluxes and vegetation dynamics. Geosci Model Dev 4(3):701-722. https://doi.org/10.5194/gmd-4-701-2011

15. Dadson SJ, Ashpole I, Harris P, Davies HN, Clark DB, Blyth E, Taylor CM (2010) Wetland inundation dynamics in a model of land surface climate: Evaluation in the Niger inland delta region. Journal of Geophysical Research Atmospheres 115(23):1-7. https://doi.org/10.1029/2010JD014474

16. Dong Z, Wang Z, Liu D, Song K, Li L, Jia M, Ding Z (2014) Mapping Wetland Areas Using Landsat-Derived NDVI and LSWI: A Case Study of West Songnen Plain, Northeast China. J Indian Soc Remote Sens 42(3):569-576. https://doi.org/10.1007/s12524-013-0357-1

17. Fei SX, Shan CU, I. H, Hua GUOZ (2011) Remote Sensing of Mangrove Wetlands Identification 10:2287-2293. https://doi.org/10.1016/j.proenv.2011.09.357

18. Gorelick N, Hancher M, Dixon M, Ilyushchenko S, Thau D, Moore R (2017) Remote Sensing of Environment Google Earth Engine: Planetary-scale geospatial analysis for everyone. Remote Sens Environ 202:18-27. https://doi.org/10.1016/j.rse.2017.06.031

19. Gumbricht T, Roman-Cuesta RM, Verchot L, Herold M, Wittmann F, Householder E, Murdiyarso D (2017) An expert system model for mapping tropical wetlands and peatlands reveals South America as the largest 
contributor. Glob Change Biol 23(9):3581-3599. https://doi.org/10.1111/gcb.13689

20. Guo M, Li J, Sheng C, Xu J, Wu L (2017) A review of wetland remote sensing. Sensors (Switzerland) 17(4):136. https://doi.org/10.3390/s17040777

21. Hird JN, Delancey ER, Mcdermid GJ (2017) Google Earth Engine, Open-Access Satellite Data, and Machine Learning in Support of Large-Area Probabilistic Wetland Mapping. https://doi.org/10.3390/rs9121315

22. Hu S, Niu Z, Chen Y (2017) Global Wetland Datasets: a Review. Wetlands 37(5):807-817. https://doi.org/10.1007/s13157-017-0927-z

23. Igu NI, Marchant R (2017) Freshwater swamp forest use in the Niger Delta: perception and insights. Journal of Forest Research 22(1):44-52. https://doi.org/10.1080/13416979.2017.1280887

24. Junk WJ, An S, Finlayson CM, Gopal B, Květ J, Mitchell SA, Robarts RD (2013) Current state of knowledge regarding the world's wetlands and their future under global climate change: A synthesis. Aquat Sci 75(1):151-167. https://doi.org/10.1007/s00027-012-0278-z

25. Kaplan G, Avdan U (2017) Mapping and monitoring wetlands usinh Sentinel-2 satellte imagery. ISPRS Annals of the Photogrammetry, Remote Sensing and Spatial Information Sciences 4(4W4):271-277. https://doi.org/10.5194/isprs-annals-IV-4-W4-271-2017

26. Kaplan G, Avdan U (2018) Sentinel-1 and Sentinel-2 Data Fusion for Mapping and Monitoring Wetlands, (July),1-12. https://doi.org/10.20944/201807.0244.v1

27. Kaplan G, Avdan Y, Avdan U (2019) Mapping and Monitoring Wetland Dynamics Using Thermal, Optical, and SAR Remote Sensing Data. Wetlands Management - Assessing Risk and Sustainable Solutions, i, 13. https://doi.org/10.5772/intechopen.80264

28. Klemas V (2011) Remote Sensing of Wetlands: Case Studies Comparing Practical Techniques. J Coastal Res 27(3):418-427. https://doi.org/10.2112/JCOASTRES-D-10-00174.1

29. Kuenzer C, Bluemel A, Gebhardt S, Vo TQ, Dech S (2011) Remote Sensing of Mangrove Ecosystems: A Review. https://doi.org/10.3390/rs3050878

30. Lehner B, Döll P (2004) Global Lakes and Wetlands Database GLWD: Development and validation of a global database of lakes, reservoirs and wetlands. Journal of Hydrology 296 / 1-4 : 1-22. Wetlands, 296(2004), 1-7

31. Liu Y, Gong W, Hu X, Gong J (2018) Forest Type Identification with Random Forest Using, 1-25. https://doi.org/10.3390/rs10060946

32. Mahdavi S, Salehi B, Granger J, Amani M, Brisco B, Huang W (2018) Remote sensing for wetland classification: a comprehensive review. GIScience and Remote Sensing 55(5):623-658. https://doi.org/10.1080/15481603.2017.1419602

33. Mahdianpari M, Salehi B, Mohammadimanesh F, Homayouni S, Gill E (2018) The First Wetland Inventory Map of Newfoundland at a Spatial Resolution of $10 \mathrm{~m}$ Using Sentinel-1 and Sentinel-2 Data on the Google Earth Engine Cloud Computing Platform. https://doi.org/10.3390/rs11010043

34. Mahdianpari M, Salehi B, Mohammadimanesh F, Homayouni S, Gill E (2019) The first wetland inventory map of newfoundland at a spatial resolution of $10 \mathrm{~m}$ using sentinel-1 and sentinel-2 data on the Google Earth Engine cloud computing platform. Remote Sensing 11(1). https://doi.org/10.3390/rs11010043

35. Mahdianpari M, Salehi B, Mohammadimanesh F, Motagh M (2017) Random forest wetland classification using ALOS-2 L-band, RADARSAT-2 C-band, and TerraSAR-X imagery. ISPRS Journal of Photogrammetry and Remote Sensing 130:13-31. https://doi.org/10.1016/j.isprsjprs.2017.05.010

Page $14 / 25$ 
36. Mahdianpari M, Salehi B, Rezaee M, Mohammadimanesh F (2018) Very Deep Convolutional Neural Networks for Complex Land Cover Mapping Using Multispectral Remote Sensing Imagery.

https://doi.org/10.3390/rs10071119

37. Medugu N (2015) The Role of Wetlands in Mitigating the Effect of Climate Change in Nigeria. 551-564. https://doi.org/10.1007/978-3-642-38670-1_26

38. Moser L, Schmitt A, Wendleder A, Roth A (2016) Monitoring of the Lac Bam wetland extent using dualpolarized X-band SAR data. Remote Sensing 8. https://doi.org/10.3390/rs8040302

39. Murray-Hudson M, Wolski P, Cassidy L, Brown MT, Thito K, Kashe K, Mosimanyana E (2015) Remote Sensingderived hydroperiod as a predictor of floodplain vegetation composition. Wetlands Ecol Manage 23(4):603616. https://doi.org/10.1007/s11273-014-9340-z

40. Murray-Hudson M, Wolski P, Ringrose S (2006) Scenarios of the impact of local and upstream changes in climate and water use on hydro-ecology in the Okavango Delta, Botswana. J Hydrol 331(1-2):73-84. https://doi.org/10.1016/j.jhydrol.2006.04.041

41. Mwita E, Menz G, Misana S, Becker M, Kisanga D, Boehme B (2012) Mapping small wetlands of Kenya and Tanzania using remote sensing techniques. Int J Appl Earth Obs Geoinf 21(1):173-183. https://doi.org/10.1016/j.jag.2012.08.010

42. Obiefuna JN, Nwilo PC, Atagbaza AO, Okolie CJ (2013) Land Cover Dynamics Associated with the Spatial Changes in the Wetlands of Lagos/Lekki Lagoon System of Lagos, Nigeria. J Coastal Res 288(3):671-679. https://doi.org/10.2112/JCOASTRES-D-12-00038.1

43. Ogilvie A, Belaud G, Delenne C, Bailly JS, Bader JC, Oleksiak A, Martin D (2015) Decadal monitoring of the Niger Inner Delta flood dynamics using MODIS optical data. J Hydrol 523:368-383. https://doi.org/10.1016/j.jhydrol.2015.01.036

44. Ohimain E (1996) Environmental Impacts of Dredging in the Niger Delta. Habitat, 9-19

45. Olalekan El, Abimbola L-HM, M. S. and O. A. D (2014) Wetland Resources of Nigeria: Case Study of the Hadejia-Nguru Wetlands. Poultry, Fisheries \& Wildlife Sciences 2(2). https://doi.org/10.4172/2375446X.1000123

46. Ozesmi SL, Bauer ME (2002) Satellite remote sensing of wetlands. Wetlands Ecol Manage 10(5):381-402. https://doi.org/10.1023/A:1020908432489

47. Plain WS, Dong Z, Wang Z, Liu D (2014) Mapping wetland areas using Landsat-derived NDVI and LSWI: a case study of Mapping Wetland Areas Using Landsat-Derived NDVI and LSWI : A Case Study of West Songnen Plain, Northeast China., (May). https://doi.org/10.1007/s12524-013-0357-1

48. Ramsey EW, Laine SC (1997) Comparison of Landsat Thematic Mapper and High Resolution Photography to Identify Change in Complex Coastal Wetlands, 281-292

49. Rebelo LM, McCartney MP, Finlayson CM (2010) Wetlands of Sub-Saharan Africa: Distribution and contribution of agriculture to livelihoods. Wetlands Ecol Manage 18(5):557-572.

https://doi.org/10.1007/s11273-009-9142-x

50. Salehi B, Mahdianpari M, Amani M, Manesh M, Granger F, Mahdavi J, Brisco B (2019) A Collection of Novel Algorithms for Wetland Classification with SAR and Optical Data. Wetlands Management - Assessing Risk and Sustainable Solutions, i, 13. https://doi.org/10.5772/intechopen.80688

51. Schlaffer S, Chini M, Dettmering D, Wagner W (2016) Mapping Wetlands in Zambia Using Seasonal Backscatter Signatures Derived from ENVISAT ASAR Time Series. 1-24. https://doi.org/10.3390/rs8050402 
52. Slagter B, Tsendbazar N-E, Vollrath A, Reiche J (2020) Mapping wetland characteristics using temporally dense Sentinel-1 and Sentinel-2 data: A case study in the St. Lucia wetlands, South Africa. Int J Appl Earth Obs Geoinf 86:102009. https://doi.org/10.1016/j.jag.2019.102009

53. Steele-Dunne SC, McNairn H, Monsivais-Huertero A, Member S (2017) Radar Remote Sensing of Agricultural Canopies: A Review. IEEE Journal of Selected Topics in Applied Earth Observations and Remote Sensing 10(2):2249-2273. https://doi.org/10.1109/JSTARS.2016.2639043

54. Taiwo OJ, Areola O (2009) A spatial temporal analysis of wetland losses in the lagos coastal region, Southwestern Nigeria, using multi-date satellite imagery. International Geoscience and Remote Sensing Symposium (IGARSS), 3, 928-930. https://doi.org/10.1109/IGARSS.2009.5417924

55. Tana G, Letu H, Cheng Z, Tateishi R (2013) Wetlands mapping in north america by decision rule classification using MODIS and ancillary data. IEEE Journal of Selected Topics in Applied Earth Observations and Remote Sensing 6(6):2391-2401. https://doi.org/10.1109/JSTARS.2013.2249499

56. Uloacha N (2004) and I.. O. Implications of wetlands degradation for water resources management. GeoJournal, 61(2), 151-154

57. Wilen ABO, Bates MK (2015) The US Fish and Wildlife Service's. National Wetlands Inventory Project 118(1):153-169

58. Wright C, Gallant A (2007) Improved wetland remote sensing in Yellowstone National Park using classification trees to combine TM imagery and ancillary environmental data. Remote Sens Environ 107(4):582-605. https://doi.org/10.1016/j.rse.2006.10.019

59. Xing L, Tang X, Wang H, Fan W, Gao X (2018) Mapping Wetlands of Dongting Lake in China Using Landsat and Sentinel-1 Time Series At 30M. ISPRS - International Archives of the Photogrammetry, Remote Sensing and Spatial Information Sciences, XLII-3, 1971-1976. https://doi.org/10.5194/isprs-archives-XLII-3-19712018

60. Xu J, Morris PJ, Liu J, Holden J (2018) PEATMAP: Refining estimates of global peatland distribution based on a meta-analysis. Catena, 160(April 2017), 134-140. https://doi.org/10.1016/j.catena.2017.09.010

61. Younggi B, Youkyung $H$, Taebyeong $C$ (2015) Image Fusion-Based Change Detection for Flood Extent Extraction Using Bi-Temporal Very High-Resolution Satellite Images. 10347-10363.

https://doi.org/10.3390/rs70810347

\section{Figures}






Figure 1

The study region: (a) Location of the study area using the standard government classification of southern Nigeria, and the locations used in previous studies referred to in the main text: Lagos lagoon (Taiwo \& Areola, 2009), Olague forest, Apoi creek and Oguta lake (Ayanlade \& Proske, 2016); 


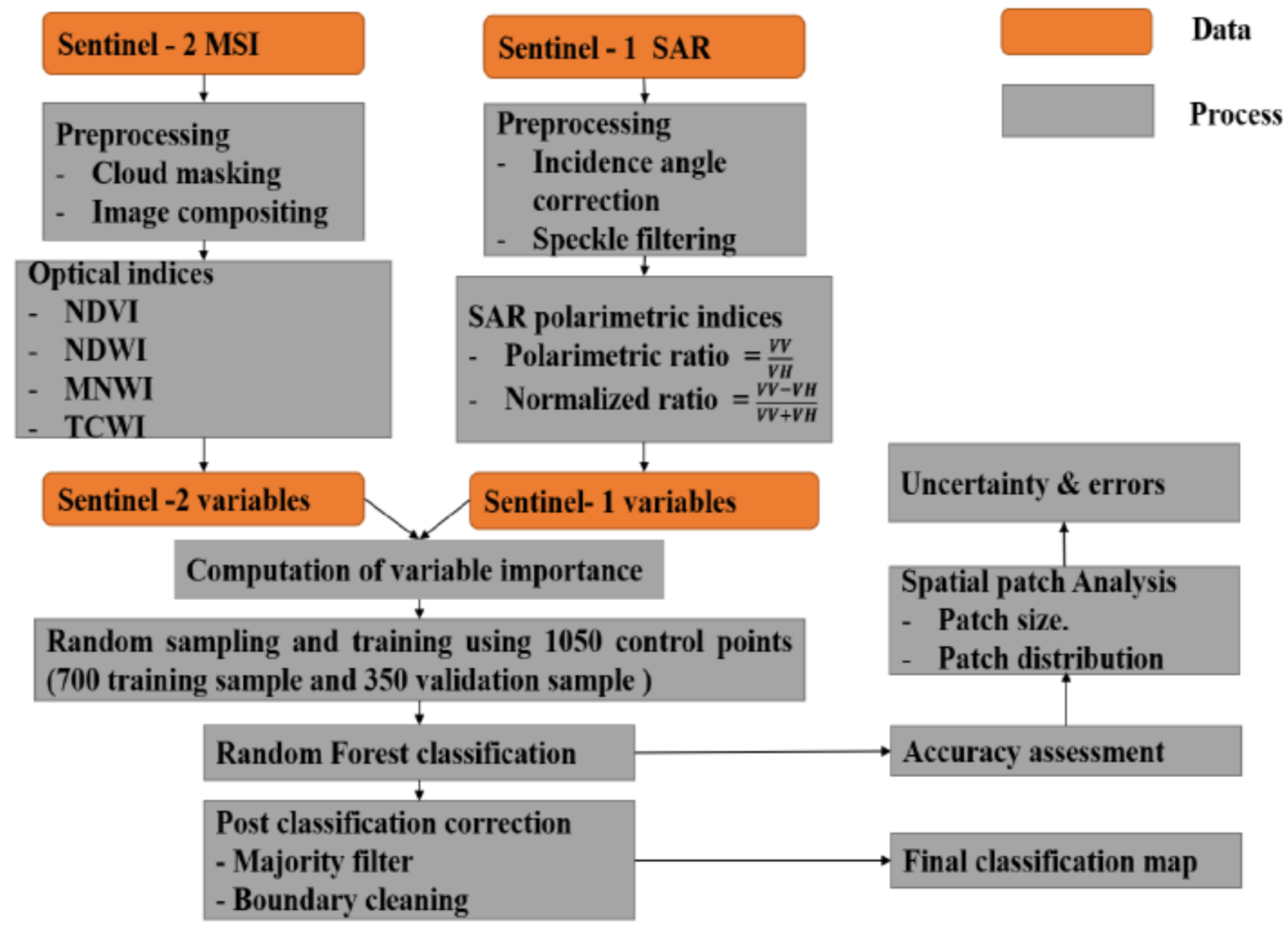

\section{Figure 2}

Methodological approach for mapping and characterization of southern Nigerian wetlands. The technique used a seasonal composite from Sentinel-2 optical imagery and Sentinel-1 radar for 2018. 


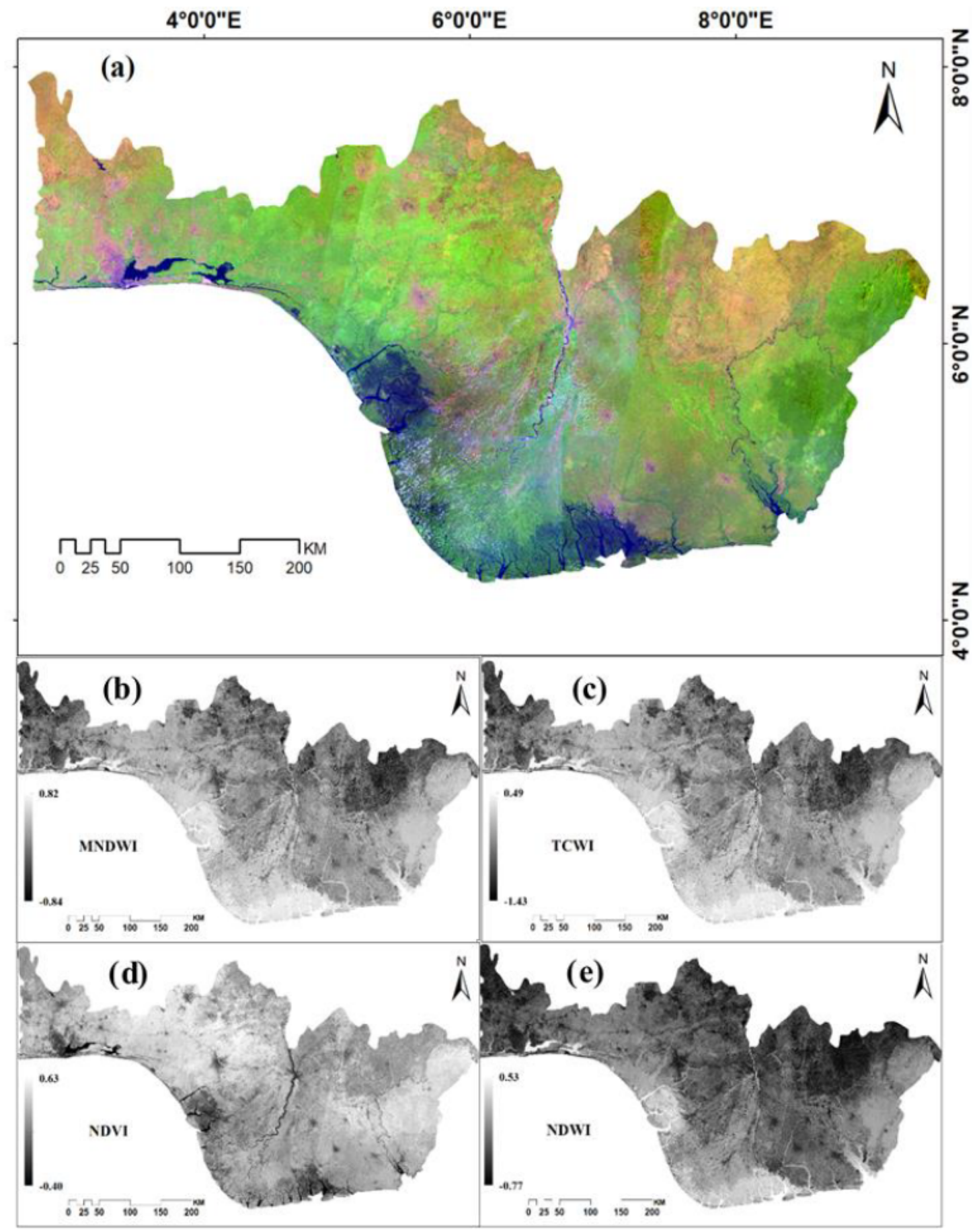

Figure 3

The Sentinel 2 composite and derived indices used for wetland classification in this study: (a) RGB composite images for Jan-Dec 2018, red (band 11), blue (band 8), green (band 2), (b) Modified Normalized Differential Water Indices (MNDWI), (c) Tasseled Cap Wetness Indices (TCWI), (d) Normalized Differential Vegetation Indices (NDVI), (e) Normalized Differential Water Indices (NDWI). The green shade in the RGB image results from reflection of vegetation, the dark blue shade represent reflection from water bodies, while urban settlement surfaces are shown in purple shade, and the lighter brown shade represents cultivated surfaces. For the indices (b-e) lighter gray shade indicates higher moisture and or vegetation value while a darker shade indicates lower values. 




Figure 4

Extracted features from Sentinel 1 composite: (a) annual composite of VV and VH polarization; (b) seasonal composite images for Jan-Dec 2018 producing a ratio polarized image; (c) seasonal composite images for JanDec 2018 producing a normalized polarized ratio image. The dry season (January- March), wet season (AprilJuly) and end of wet season (September-November) composites were inserted into the red, green and blue channels respectively. The bright yellow shade in (b) and bright white in (c) shows high backscatter from urban areas in the red and green channels. The dark blue and black shade are the result of low backscatter from cultivated areas and water features. 


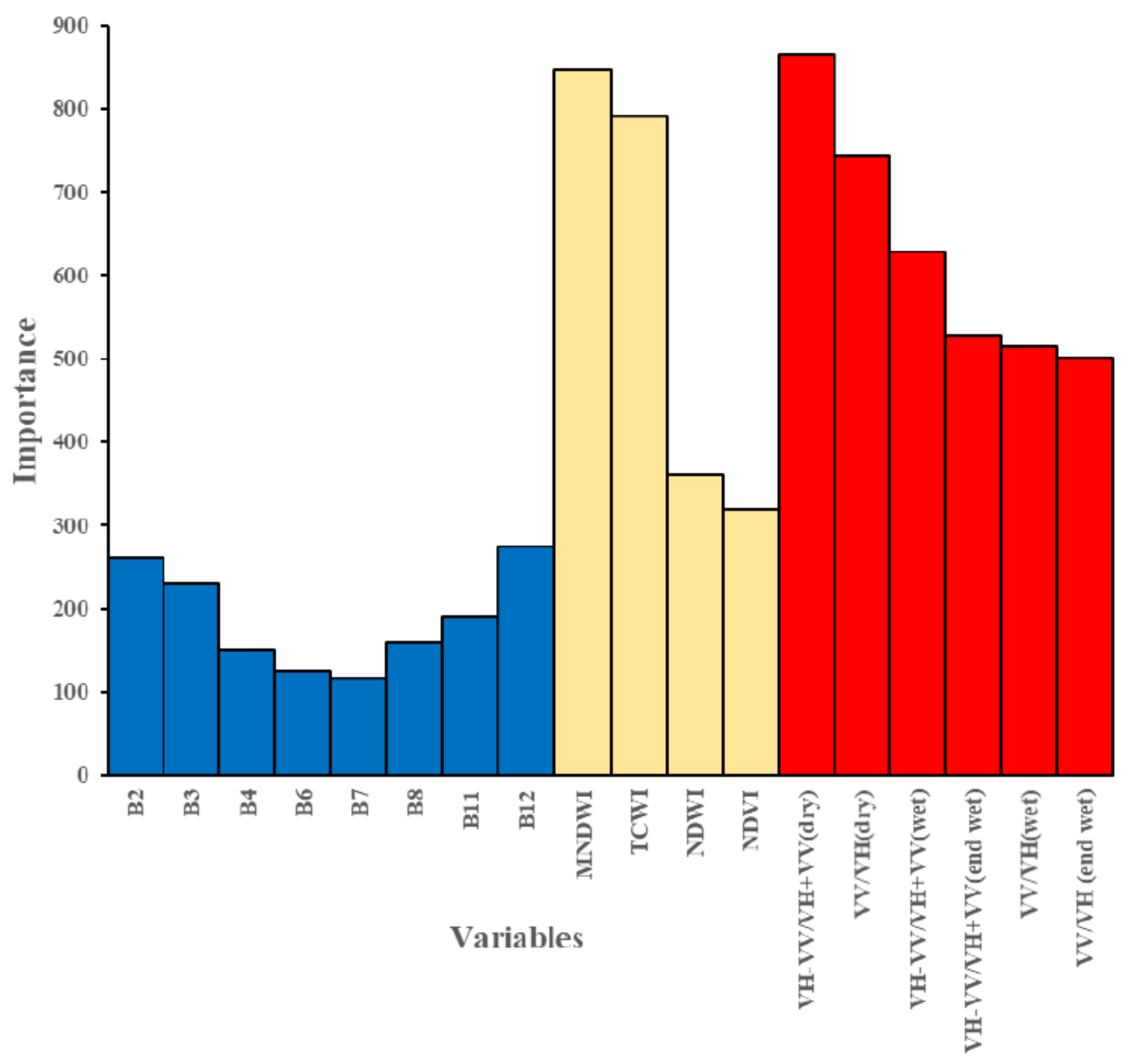

Figure 5

The importance of each extracted Sentinel-1 and Sentinel-2 features using the training dataset for Random forest classification. The importance of the variable is the sum of decrease impurity each time the variable is selected to be split at the node for the entire trees in the forest and is unitless. The blue bars illustrate the importance of the optical bands, the light yellow shows optical indices and SAR polarimetric indices is represented by red bars. 


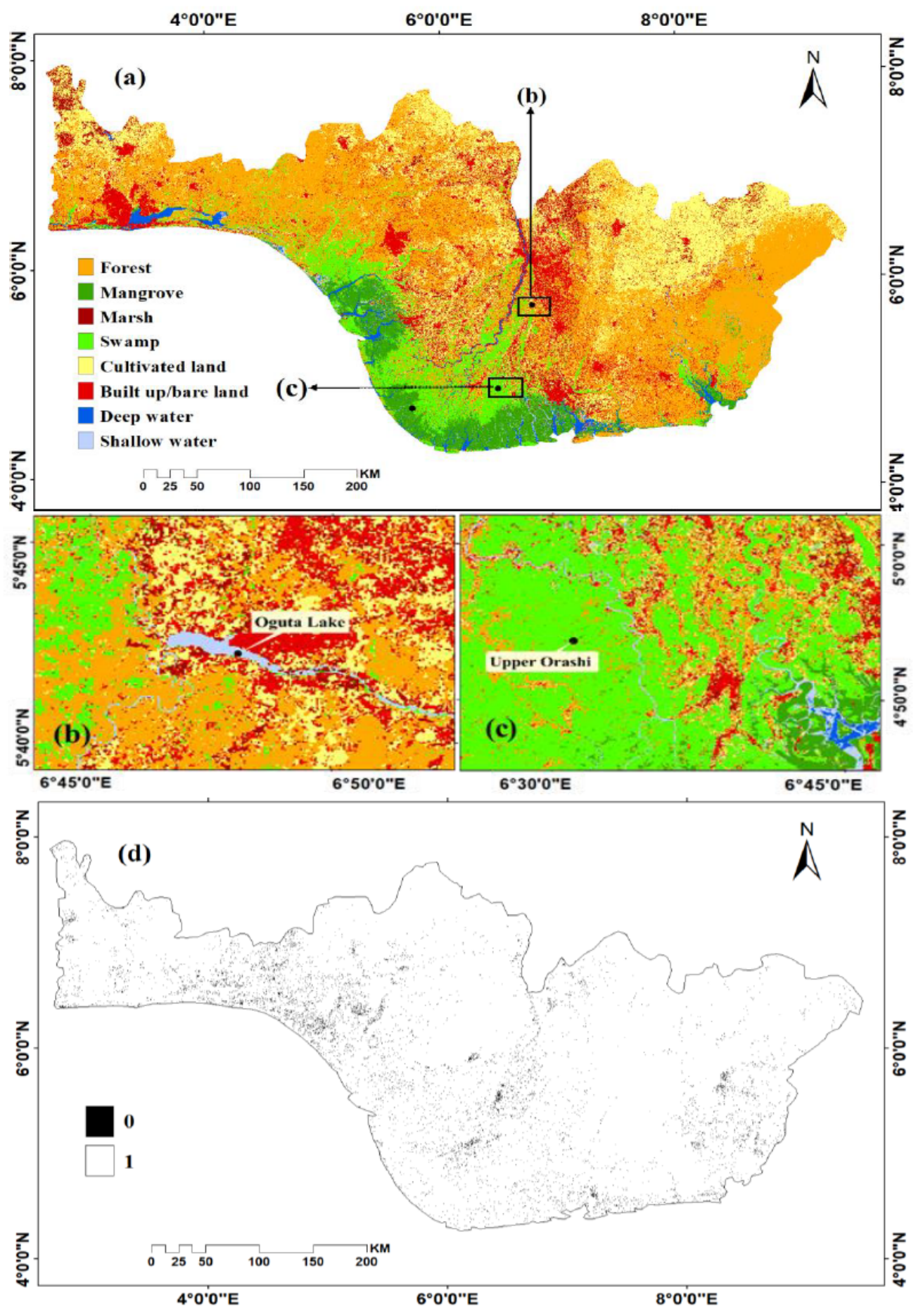

Figure 6

Final land cover map of southern Nigeria for 2018 obtained from RF classification of indices derived from Sentinel-2 optical data and Sentinel-1 SAR data (a), with inset (b) showing Oguta Lake and inset (c) showing Upper Orashi forest, both being examples of Ramsar wetlands while (d) displays the spatial distribution of uncertainty where the value 1 in white shade shows matching landcover class and the value 0 in black shade indicates a mismatch class from the comparison of a map produced using the entire control point dataset with a map produced from a randomly selected subset (70\%) of control points. 

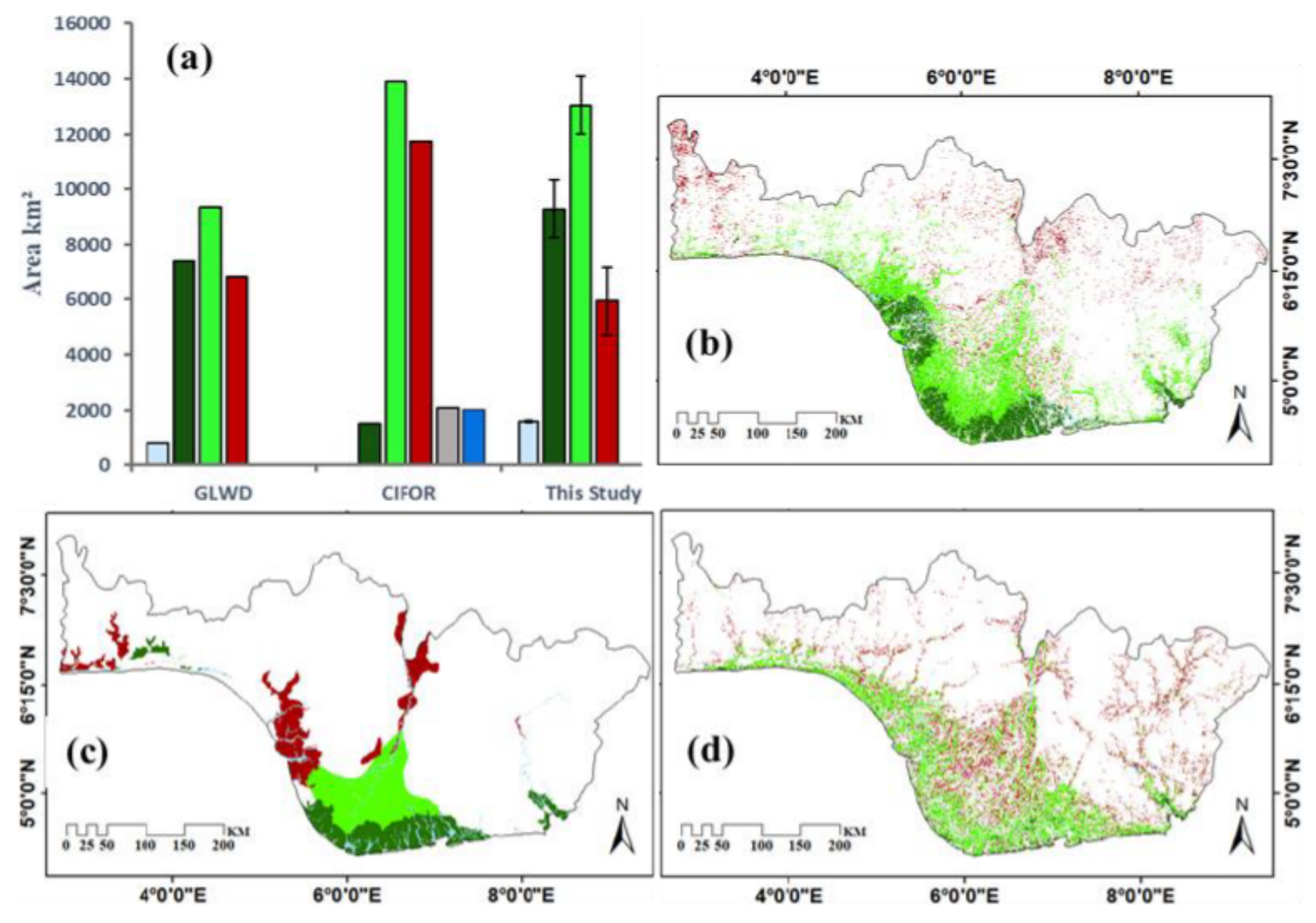

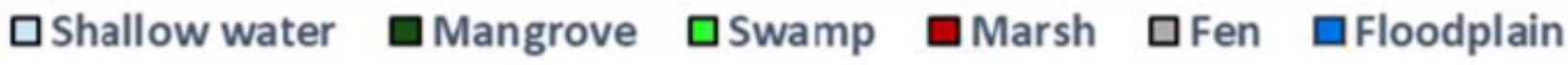

Figure 7

A comparison of wetland map products for southern Nigeria: (a) areas of different wetland classes in southern Nigeria - error bars show misclassification levels based accuracy achieved for each wetland type in our study; (b) map of southern Nigeria covered by wetlands identified in our study showing only the wetland classes; (c) the Global Lakes and Wetlands Database (GLWD) by Lehner and Döll (2004) and (d) the global wetland database by the Center for International Forestry Research (CIFOR). 

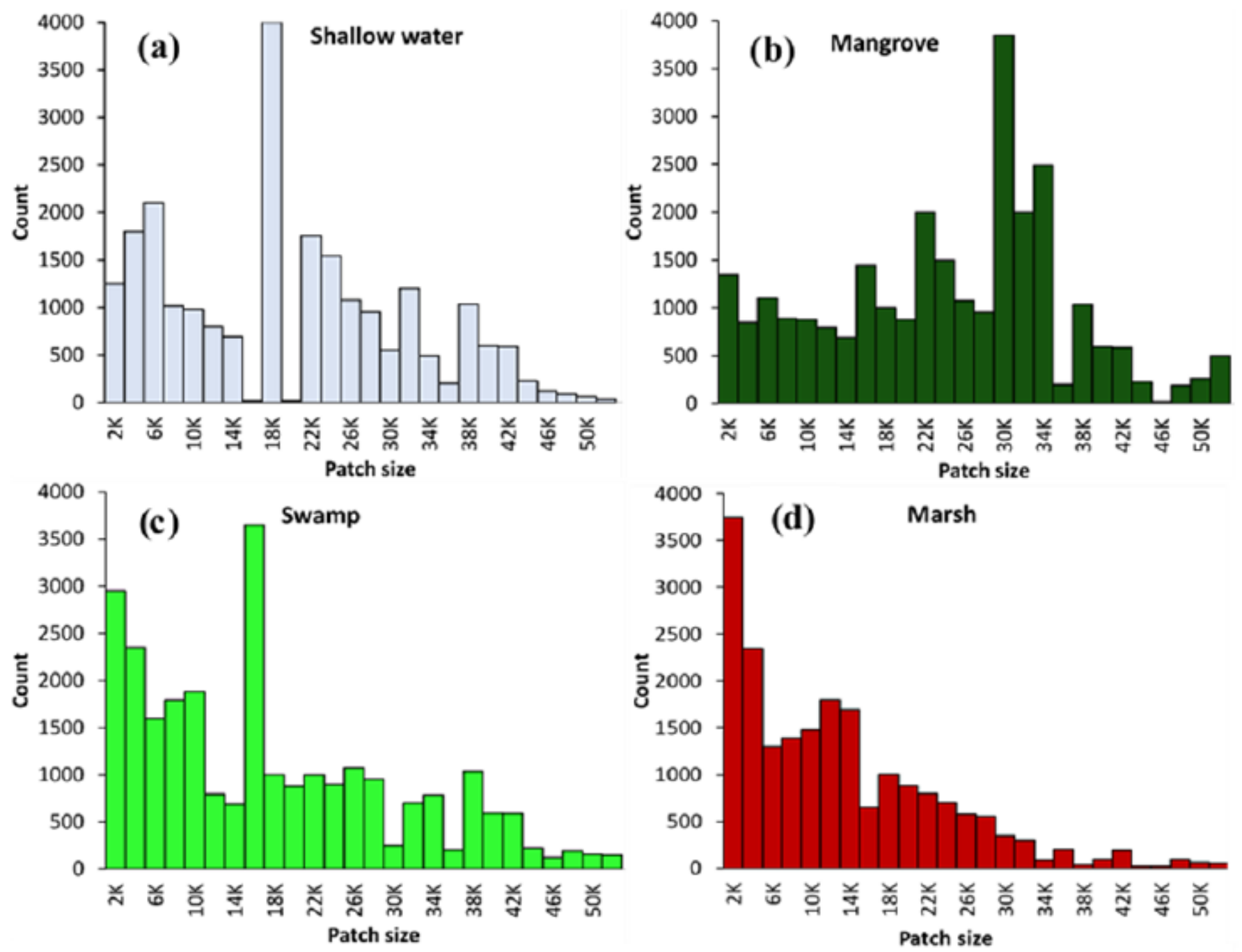

Patch size $=$ Total number pixels in a patch

Patch area $(\mathrm{km})=$ Total number pixels $\times$ pixel area $\left(10^{2}\right) \times 10^{-6}$

\section{Figure 8}

Distribution of patch size for different wetland classes: (a) shallow water; (b) mangrove; (c) swamp; (d) marsh. The patch size is defined as the number of pixels within a patch, the count is the frequency of patches with number of pixels in each category. 


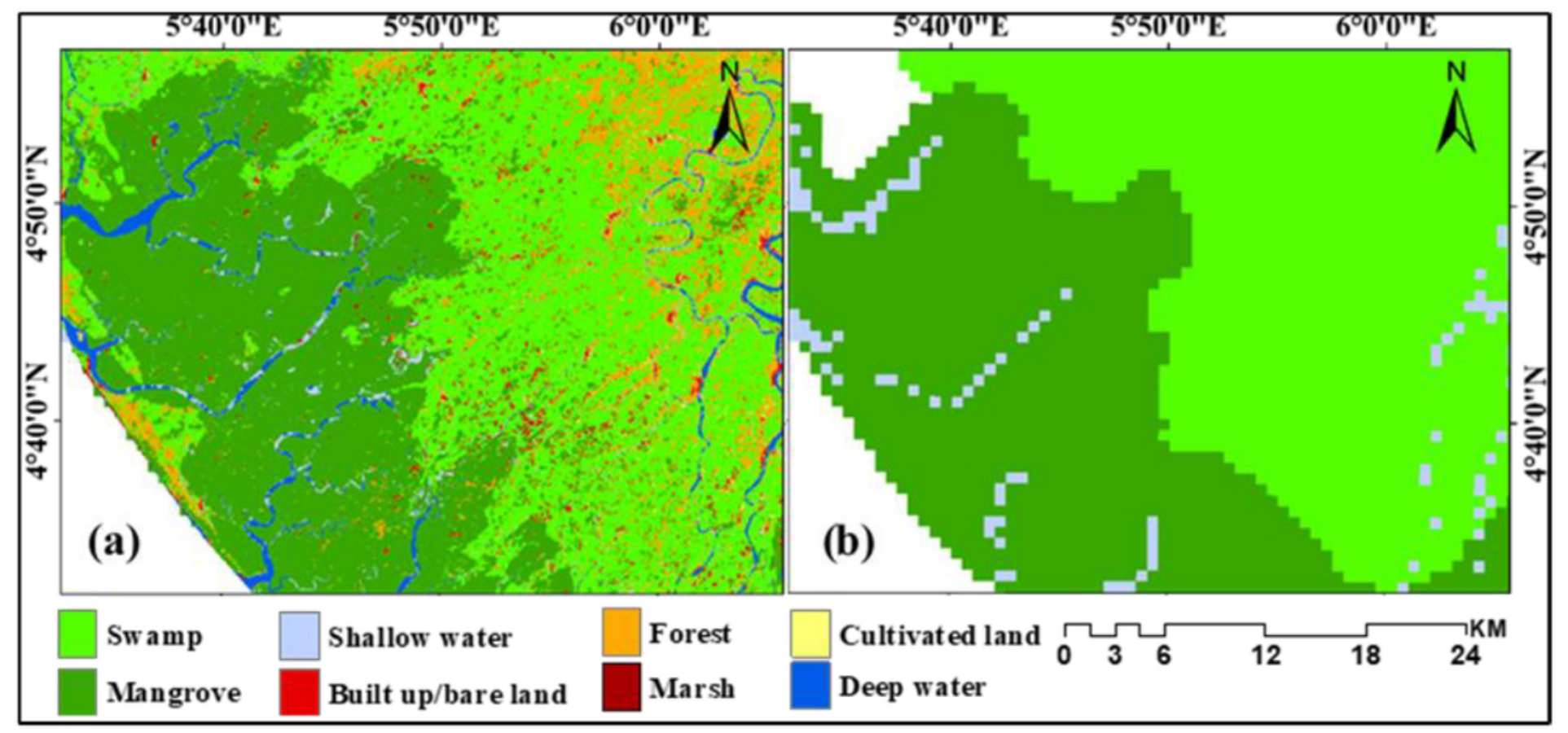

Figure 9

Comparison, for the same geographical area, between delineated wetland cover from: (a) this study using high resolution Sentinel data (full map shown in Figure 6a), and (b) GLWD from a combination of low-resolution data. 